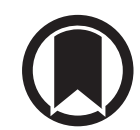

CrossMark

\title{
Diffuse idiopathic pulmonary neuroendocrine cell hyperplasia syndrome
}

\author{
Giulio Rossi ${ }^{1}$, Alberto Cavazza ${ }^{2}$, Paolo Spagnolo ${ }^{3,4}$, Nicola Sverzellati $^{5}$, \\ Lucia Longo ${ }^{6}$, Agita Jukna ${ }^{7}$, Gloria Montanari ${ }^{8}$, Cristiano Carbonelli $^{9}$, \\ Giada Vincenzi ${ }^{10}$, Giuseppe Bogina ${ }^{11}$, Renato Franco $^{12}$, Marcello Tiseo ${ }^{13}$, \\ Vincent Cottin ${ }^{14,15,16}$ and Thomas V. Colby ${ }^{17}$
}

\begin{abstract}
Affiliations: ${ }^{1}$ Section of Pathologic Anatomy, University Hospital Policlinico of Modena, Modena, Italy. ${ }^{2}$ Dept of Oncology and Advanced Technologies, Operative Unit of Oncology, Arcispedale S. Maria Nuova/I.R.C.C.S., Reggio Emilia, Italy. ${ }^{3}$ Medical University Clinic, Canton Hospital Baselland and University of Basel, Basel, Switzerland. ${ }^{4}$ Section of Respiratory Diseases, Dept of Cardiac, Thoracic and Vascular Sciences, University of Padova, Padova, Italy. ${ }^{5}$ Section of Diagnostic Imaging, Dept of Surgery, University of Parma, Parma, Italy. ${ }^{6}$ Medical Oncology Unit, Civic Hospital "Ramazzini", Carpi, Italy. ${ }^{7}$ Pathology Institute, Pauls Stradins Clinical University Hospital, Riga, Latvia. ${ }^{8}$ Respiratory Disease Clinic, University Hospital Policlinico di Modena, Modena, Italy. ${ }^{9}$ Operative Unit of Pulmonology, Arcispedale S. Maria Nuova/I.R.C.C.S., Reggio Emilia, Italy. ${ }^{10}$ Dept of Life Sciences, University of Modena and Reggio Emilia, Modena, Italy. ${ }^{11}$ Section of Pathologic Anatomy, Hospital "Don Calabria”, Verona, Italy. ${ }^{12}$ Pathologic Anatomy, Istituto Nazionale Tumori Fondazione "Pascale", Naples, Italy. ${ }^{13}$ Division of Medical Oncology University Hospital, Parma, Italy. ${ }^{14}$ Hospices Civils de Lyon, Hôpital Louis Pradel, National Reference Center for Rare Pulmonary Diseases, Lyon, France. ${ }^{15}$ Claude Bernard Lyon 1 University, University of Lyon, Lyon, France. ${ }^{16}$ INRA, UMR754, Lyon, France. ${ }^{17}$ Dept of Laboratory Medicine and Pathology, Mayo Clinic, Scottsdale, AZ, USA.
\end{abstract}

Correspondence: Paolo Spagnolo, Respiratory Disease Unit, Dept of Cardiac, Thoracic and Vascular Sciences, University of Padova, via Giustiniani 3, 35128 Padova, Italy. E-mail: paolo.spagnolodunipd.it

ABSTRACT The term diffuse idiopathic pulmonary neuroendocrine cell hyperplasia (DIPNECH) may be used to describe a clinico-pathological syndrome, as well as an incidental finding on histological examination, although there are obvious differences between these two scenarios. According to the World Health Organization, the definition of DIPNECH is purely histological. However, DIPNECH encompasses symptomatic patients with airway disease, as well as asymptomatic patients with neuroendocrine cell hyperplasia associated with multiple tumourlets/carcinoid tumours. DIPNECH is also considered a preneoplastic lesion in the spectrum of pulmonary neuroendocrine tumours, because it is commonly found in patients with peripheral carcinoid tumours.

In this review, we summarise clinical, physiological, radiological and histological features of DIPNECH and critically discuss recently proposed diagnostic criteria. In addition, we propose that the term "DIPNECH syndrome" be used to indicate a sufficiently distinct patient subgroup characterised by respiratory symptoms, airflow obstruction, mosaic attenuation with air trapping on chest imaging and constrictive obliterative bronchiolitis, often with nodular proliferation of neuroendocrine cells with/without tumourlets/carcinoid tumours on histology. Surgical lung biopsy is the diagnostic gold standard. However, in the appropriate clinical and radiological setting, transbronchial lung biopsy may also allow a confident diagnosis of DIPNECH syndrome.

@ERSpublications

DIPNECH embraces a range of conditions; we suggest the term DIPNECH syndrome to indicate a distinct patient subset http://ow.ly/YHwuK

Earn CME accreditation by answering questions about this article. You will find these at erj.ersjournals.com/misc/cmeinfo.xhtml

Received: Nov 232015 | Accepted after revision: Feb 152016 | First published online: April 132016

Conflict of interest: Disclosures can be found alongside the online version of this article at erj.ersjournals.com

Copyright CERS 2016 


\section{Background and current definition}

Diffuse idiopathic pulmonary neuroendocrine cell hyperplasia (DIPNECH) is a rare and poorly understood pulmonary disorder that is being reported with increasing frequency. Initially described as peripheral and multiple bronchial adenomas [1], DIPNECH was not fully recognised and named until 1992, when AguAYo et al. [2] reported on six nonsmoking patients (mainly females) with cough, exertional dyspnoea and an obstructive or mixed obstructive/restrictive defect on pulmonary function test who, on histological examination of the lung, had diffuse hyperplasia and dysplasia of pulmonary neuroendocrine cells, multiple carcinoid tumourlets and peribronchiolar fibrosis obliterating small airways (e.g. constrictive obliterative bronchiolitis). Pulmonary neuroendocrine cells have paracrine functions and are thought to play an important role in lung development $[3,4]$. Indeed, they are frequently found in the airways of fetal and neonatal lungs, but decrease in density with age and are only present focally in adult airways $[5,6]$.

Histologically, DIPNECH may manifest as: 1) generalised proliferation of scattered neuroendocrine cells; 2) tiny nodular aggregates (neuroendocrine bodies); or 3) linear proliferation of neuroendocrine cells [7]. Although usually confined to the bronchial and bronchiolar epithelium, these proliferations can extend beyond the basement membrane to form tumourlets (discrete neuroendocrine cell aggregates $<5 \mathrm{~mm}$ in diameter) or carcinoid tumours (nodules $>5 \mathrm{~mm}$ in diameter). DIPNECH is recognised by the 2015 World Health Organization (WHO) classification of lung tumours as a pre-neoplastic lesion [5]. In fact, while overall there are insufficient well-documented data to support it as a pre-neoplastic condition, DIPNECH is generally thought of as a precursor for malignancy. Foci of neuroendocrine cell hyperplasia $(\mathrm{NECH})$ may be found in a number of conditions in which they are thought to be reactive (e.g. exposure to tobacco smoke, bronchopulmonary dysplasia, cystic fibrosis, asthma, diffuse panbronchiolitis, chronic exposure to high altitude, bronchiectasis and pulmonary fibrosis) [8]; however, DIPNECH is considered a primary neuroendocrine cell proliferation often accompanied by constrictive obliterative bronchiolitis [2, 9].

To date, DIPNECH has only been reported in case reports and in small case series. No consensus radiological and/or pathological criteria exist for diagnosis. DIPNECH is defined by the WHO as "generalised proliferation of scattered single cells, small nodules (neuroendocrine bodies) or linear proliferation of pulmonary neuroendocrine cells that may be confined to the bronchial and bronchiolar epithelium, include local extraluminal proliferation in the form of tumourlets, or extend to the development of carcinoid tumours" [5]. However, this definition does not provide criteria on when the presence of NECH should be considered "diffuse", "idiopathic" or "pre-neoplastic". Recently, MARCHEvsKy et al. [10] reported on 70 consecutive surgical lung biopsies with multifocal neuroendocrine proliferations (including $\mathrm{NECH}$ and/or more than one carcinoid tumourlet) diagnosed at their institution between 1993 and 2013. Of note, of the 540 carcinoid tumours and 180 lung specimens with one or more carcinoid tumourlet diagnosed during that timeframe, only these 70 cases displayed multifocal NECH in bronchiolar epithelium and/or at least two tumourlets. Of these cases, $87 \%$ (61 out of 70) were females with a mean age of 72 years, and the majority of patients $(57(81 \%)$ out of 70$)$ had undergone surgery for a lung nodule/mass. Importantly, and in contrast to the patients originally described by AGUAYo et al. [2], none of these cases had either histological features of constrictive obliterative bronchiolitis or had been diagnosed clinically as DIPNECH before histological examination [10]. The authors also showed that the presence of at least five neuroendocrine cells, isolated or in clusters, located within the basement membrane of the bronchiolar epithelium of at least three bronchioles in combination with at least three carcinoid tumourlets (and in the absence of conditions that could result in secondary NECH) can be used to diagnose DIPNECH in surgical lung biopsy specimens. In other words, they proposed that variable manifestations of NECH in a patchy distribution involving only some bronchioles along with a variable number of tumourlets, instead of diffuse NECH involving most bronchioles, may be sufficient to reliably diagnose DIPNECH [10].

Pathologists may encounter NECH in a variety of settings such as: 1) constrictive obliterative bronchiolitis in obstructive pulmonary disease; 2) peripheral carcinoid tumours as an incidental finding without clinical relevance (generally in asymptomatic patients with normal pulmonary function tests); or 3) reactive proliferation adjacent to infection, primary or metastatic cancers, or in the context of chronic pulmonary diseases, such as pneumoconiosis, smoking-related interstitial lung disease, radiation pneumonitis, exogenous lipoid pneumonia and pulmonary fibrosis (table 1) [1, 11-19].

In addition, while the diagnosis of NECH is purely histological, patients with DIPNECH usually have clinical symptoms (cough and dyspnoea), airflow obstruction secondary to peribronchiolar fibrosis and constrictive obliterative bronchiolitis and characteristic high-resolution computed tomography findings. Overall, those are very different scenarios and we believe they should be more formally separated.

In this article, we reappraise the concept of DIPNECH within the spectrum of neuroendocrine cell proliferations in the lung, and propose that DIPNECH syndrome be considered synonymous with the condition described by Aguayo et al. [2] (e.g. a unique clinical, radiological and pathological entity) and kept separate from conditions characterised by NECH but primarily identified histologically. 
TABLE 1 Settings in which DIPNECH syndrome and NECH may be encountered

DIPNECH syndrome

Other forms of NECH

Obstructive lung disease
Hypoxaemia
Pneumoconiosis
Smoking-related diseases
Primary lung cancer
Carcinoid tumours
Metastatic lung cancer
Infections
Interstitial lung disease

$\begin{array}{cc}+ & - \\ +/- & + \\ - & + \\ - & + \\ - & + \\ + & + \\ - & + \\ - & + \\ - & +\end{array}$

DIPNECH: diffuse idiopathic pulmonary neuroendocrine cell hyperplasia; NECH: neuroendocrine cell hyperplasia.

\section{Clinical features}

The most common clinico-radiological features of DIPNECH syndrome and other forms of NECH identified histologically are summarised in table 2 .

Demographic characteristics of DIPNECH are different from those of reactive NECH and of tumourlets/ carcinoid tumours. DIPNECH occurs predominantly in females (female-to-male ratio of approximately 10:1) with a mean age of 58 years, and is not associated with smoking [2, 5, 7, 20, 21]. Conversely, carcinoid tumours preferentially occur in younger patients and, similar to reactive proliferation of neuroendocrine cells, have no clear sex predilection $[22,23]$. DIPNECH syndrome is typically characterised by an insidious onset with chronic nonproductive cough, exertional dyspnoea and wheezing, which are spuriously attributed to asthma, chronic obstructive pulmonary disease or gastro-oesophageal reflux disease $[2,5,7,20,21]$. Indeed, the diagnosis of DIPNECH is usually made several years after the onset of clinical symptoms, often following the incidental discovery of a lung nodule (or nodules) on imaging, usually computed tomography (CT), during investigations for other diseases or follow-up of extrathoracic malignancies [2, 5, 7, 20, 21, 24]. Other settings in which DIPNECH has been diagnosed include type 1 multiple neuroendocrine neoplasia and ectopic secretion of adrenocorticotropic and growth hormone [5, 7, 20,21, 25-30]. Lung function tests reveal an obstructive or mixed obstructive/restrictive ventilatory defect in the vast majority of cases, whereas a purely restrictive pattern is rare $[2,5,7,20,21]$. Some patients with DIPNECH may also have normal spirometry. The clinical course is characterised by a slowly progressive functional decline or long-term stability; however, a rapidly progressive and life-threatening clinical course has also been reported in a small subset of patients $(<10 \%)[2,5,7,20,21,24,25]$.

\section{TABLE 2 Clinico-pathological and computed tomography (CT) features of DIPNECH syndrome and $\mathrm{NECH}$}

DIPNECH syndrome

Other forms of NECH

Clinical features
Age years
Sex
Symptoms
Pulmonary function abnormality
Presence of carcinoid
Constrictive bronchiolitis
CT features
Mosaic perfusion
Nodules
Mucoid impaction
Bronchiectasis
Bronchial wall thickening
Atelectasis

$50-60$
Mostly females
$+/-$
$+/-$
$+1-$
+
+
+
$+1-$
$+1-$
$+1-$
$+1-$

$30-70$
Mainly females
-
-
$+{ }_{-}^{\#}$
-

-
+
-
-
-
-

DIPNECH: diffuse idiopathic pulmonary neuroendocrine cell hyperplasia; $\mathrm{NECH:} \mathrm{neuroendocrine} \mathrm{cell}$ hyperplasia. ${ }^{\#}$ : bronchial carcinoids with peritumoral tumourlets may be seen. 


\section{Radiological features}

A diagnosis of DIPNECH is virtually impossible on conventional chest radiography, particularly in asymptomatic patients. CT abnormalities are those of airway-related diseases, and include mosaic attenutation (figure 1a), bronchial wall thickening, bronchiectasis and mucoid impactions (figure 1b). However, mosaic attenuation with air trapping, which is due to constrictive bronchiolitis and is characterised by a patchwork of low-attenuation lung that is interposed with normally ventilated higher attenuation lung, is the predominant finding (figure 1b) [5, 7, 8, 20, 21, 31-33]. Mosaic attenuation and air trapping, which can be the sole and indirect features of small airway obstruction, are better appreciated on expiratory CT scans $[5,7,8,20,21,31-33]$. The growth of neuroendocrine cells may also manifest as nodular aggregates of various size in the lung parenchyma (figure $1 \mathrm{c}$ and $\mathrm{d}$ ). In fact, nodules are the most common findings in DIPNECH and may be the sole or predominant abnormality. They are round-to-ovoid, generally of solid density or ground-glass attenuation and correspond to either tumourlets $(<5 \mathrm{~mm})$ or carcinoid tumours $(>5 \mathrm{~mm})$ depending on their size [5, 8, 31-33]. More than $60 \%$ of patients with DIPNECH have multiple nodules, usually with a unique or a few dominant lesions corresponding to carcinoid tumours and tiny, ground-glass, nodular bronchiolocentric opacities corresponding to tumourlets $[5,7,8,20,21,31-33]$.

In the appropriate clinical (e.g. middle-aged female, nonsmoker, with obstructive or mixed obstructive/ restrictive ventilatory defect) and radiological (e.g. combination of small nodules, features of constrictive bronchiolitis and mosaic attenuation) setting, experienced thoracic radiologists may suggest a diagnosis of DIPNECH. In such context, transbronchial lung biopsy may allow a confident diagnosis of DIPNECH syndrome [21], although surgical lung biopsy remains the diagnostic "gold standard" [5, 7, 8, 20, 21, 31-33]. DIPNECH syndrome can be diagnosed based on clinical data and imaging features alone (e.g. without histology), although with unclear specificity [21].

\section{Histological features}

A spectrum of histological abnormalities can be observed in DIPNECH syndrome. Indeed, NECH may appear as a generalised proliferation of scattered neuroendocrine cells, linear proliferation or micronodules (neuroendocrine bodies) (figure 2) [1]. Linear growth of scattered neuroendocrine cells along the
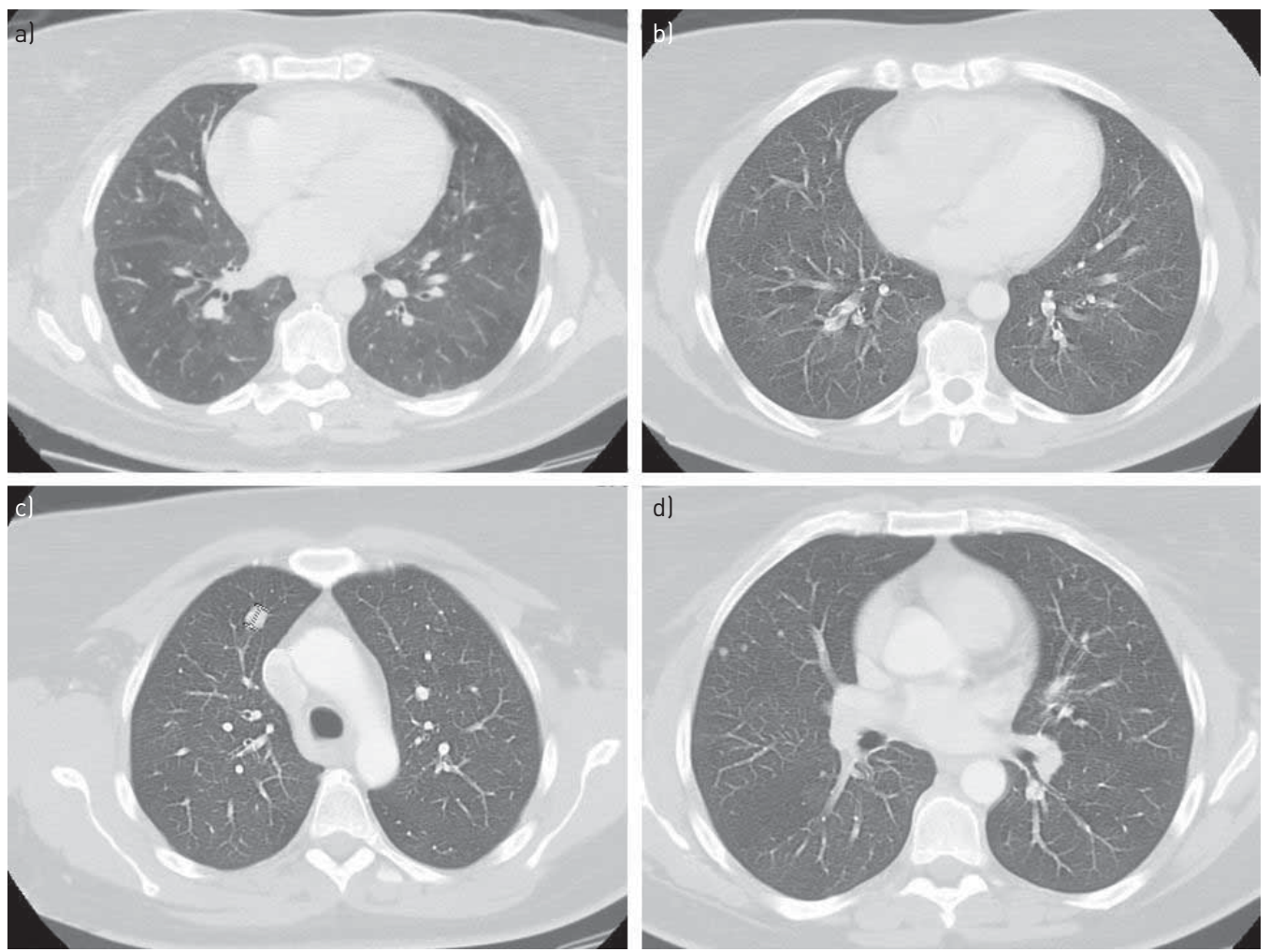

FIGURE 1 Computed tomography scan of a 47-year-old female with diffuse idiopathic pulmonary neuroendocrine cell hyperplasia showing a) mosaic attenuation, b) bronchial thickening and several nodules of different size corresponding to c) typical carcinoid and d) tumourlets. 

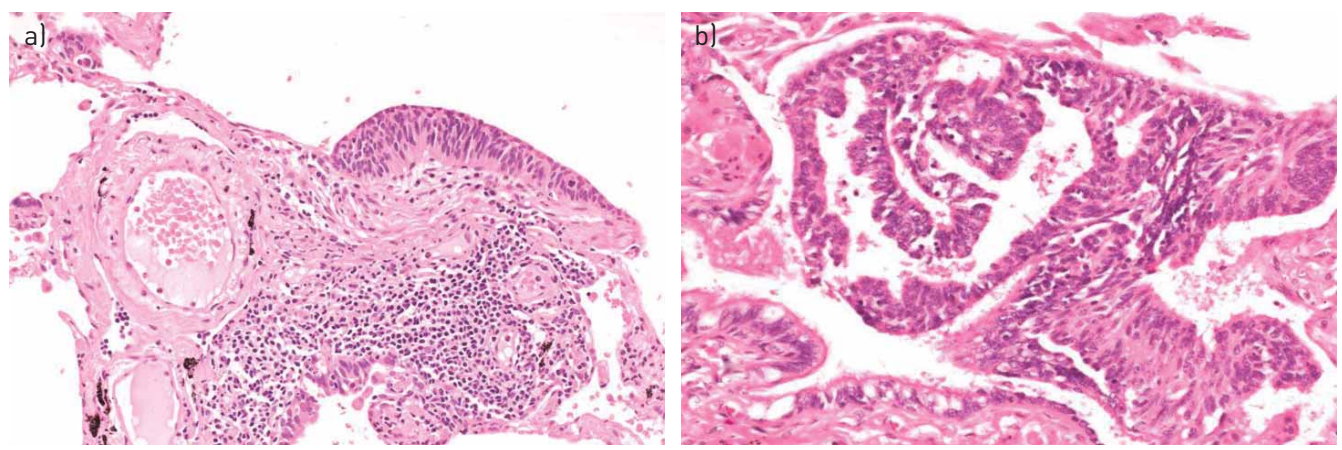

FIGURE 2 Linear neuroendocrine cell hyperplasia with thickening of the a) bronchiolar mucosa and b) intrabronchiolar growth.

bronchiolar mucosa may be difficult to appreciate without specific neuroendocrine markers (particularly chromogranin A and synaptophysin) [5]. Tumourlets are tiny $(<5 \mathrm{~mm})$, irregular neuroendocrine cell growths infiltrating the basal membrane of the bronchioles (figure 3). Carcinoid tumours are $>5 \mathrm{~mm}$ in size and subdivided into typical and atypical according to their mitotic rate $(<2$ or $2-10 \times 10$ high-power-fields, respectively) and the presence of punctate necrosis [5, 22, 34].

Constrictive obliterative bronchiolitis, which represents the histological hallmark of DIPNECH, is characterised by mild, chronic inflammatory cell infiltrate, wall thickening and fibrosis of involved airways that lead to progressive narrowing and, in severe cases, complete obliteration of the bronchiolar lumen (figure 4) [20]. Constrictive obliterative bronchiolitis is thought to result from neuroendocrine cell production of potentially fibrogenic cytokines, such as bombesin, although the presence of associated inflammation may be a contributing factor $[20,35]$.

\section{Immunohistochemical features}

All neuroendocrine proliferations observed in NECH and DIPNECH express the most common markers of neuroendocrine cell differentiation, such as chromogranin A, synaptophysin and CD56, as well as the less specific antibodies for neuron-specific enolase and PGP9.5. Thyroid transcription factor-1 is also commonly expressed, but the intensity of the staining is weak-to-moderate and not specific for neuroendocrine cells (figure 5) [5, 22, 34]. Neuroendocrine cells constantly stain positive for CD10, whereas expression of gastrin-releasing peptide (bombesin), bcl-2, retinoblastoma protein, p27 and calcitonin is variable. Staining for oestrogen and progesterone receptors, CDX2, c-KIT (CD117), p63, p40, napsin, high-molecular weight cytokeratins, adrenocorticotropic hormone, human gonadotropin- $\alpha$, corticotropin-releasing hormone, met-enkephalin, vasoactive intestinal polypeptide, neurotensin and growth hormone-releasing hormone is generally negative $[5,22,23,34,36-40]$.

Expression of somatostatin receptors type 2 and mammalian target of rapamycin (mTOR) signalling activation patterns has also been reported [41-43]. Finally, expression of p53, Ki67 and p16 is seen more consistently and earlier in DIPNECH than in reactive neuroendocrine cell proliferations $[5,22,23]$.
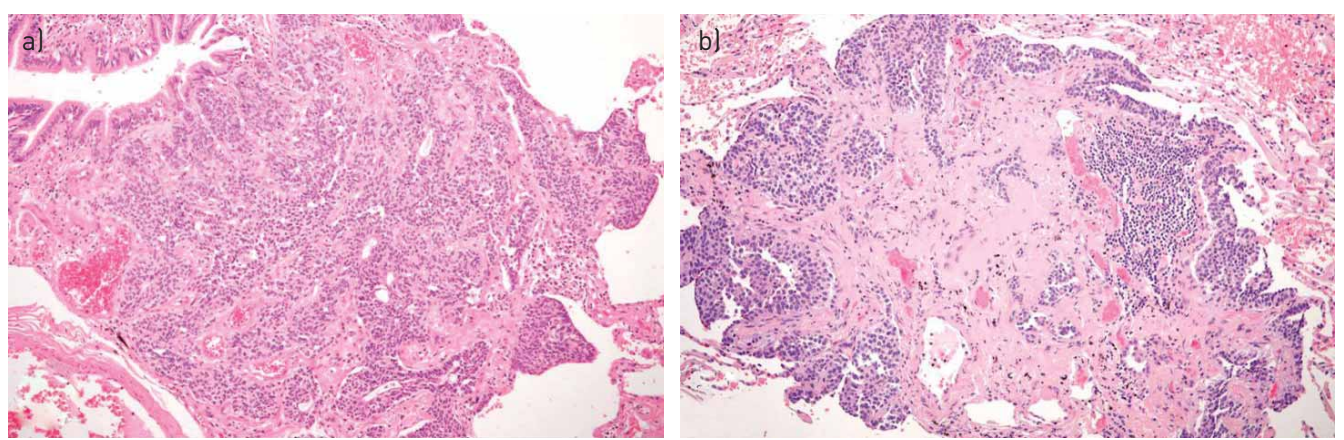

FIGURE 3 A tumourlet surrounding al a bronchiole and b) completely obscuring the bronchial lumen with fibrotic stroma. 

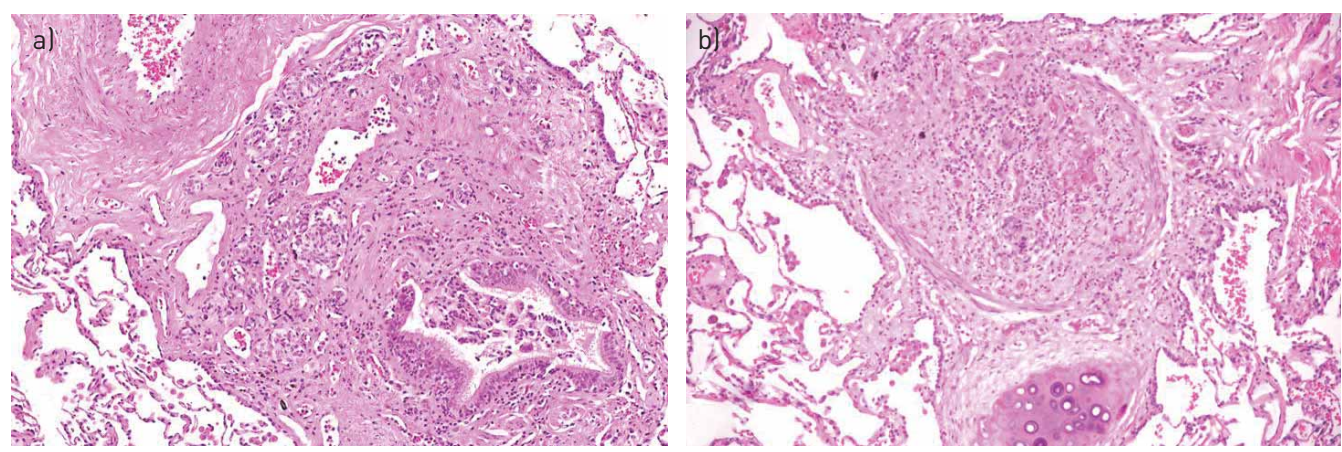

FIGURE 4 Constrictive obliterative bronchiolitis in different phases of progression. a) Partial narrowing of the lumen and b) complete obliteration of the bronchiole.

\section{Differential diagnosis}

Neuroendocrine cell growths and tumourlets may be confused with meningothelial cell proliferations/ nodules [44, 45]. Meningothelial cell lesions may be solitary or multiple and are characterised by a perivascular rather than bronchiolar proliferation. In addition, these cells are spindle shaped, and often show nuclear pseudoinclusions along with immunoprofile of meningiomas [44, 45]. Positive staining with CD56 may be misleading since both neuroendocrine cells and meningothelial-like proliferations may express CD56 [44].

Once a diagnosis of NECH is established, the next crucial step is to identify possible underlying causes and discriminate DIPNECH from other forms of NECH. This requires the availability of clinical, functional and imaging data. However, a meticulous examination of the lung specimen, particularly looking for the presence of constrictive obliterative bronchiolitis, may suggest the diagnosis of DIPNECH. From a clinical standpoint, the main differential diagnosis is metastatic cancer of the lung, particularly when patients with DIPNECH have previous history of cancer $[5,7,20,21]$.

\section{Management and prognosis}

Data on treatment, long-term follow-up and outcomes in patients with DIPNECH are limited. Therapeutic options have included oral and inhaled steroids, chemotherapy, surgical lung resection and lung transplantation, as well as clinical observation alone for mild and stable cases $[5,7,20,21]$. Despite the lack of clear evidence of efficacy, the majority of symptomatic patients are treated with steroid-based therapy [20]. Corticosteroids may reduce the inflammatory response induced by neuroendocrine cell-secreted neuropeptides [35], and may improve symptoms. Conversely, cytotoxic agents are largely ineffective and not recommended. Octreotide, a somatostatin analogue shown to reduce the hormonal hypersecretion of neuroendocrine cells in gastrointestinal and bronchial carcinoids [46], has been used with some success, particularly in the presence of somatostatin receptors [47]. CHAUHAN and RAmirez [47] retrospectively evaluated five cases of DIPNECH among 184 cases of primary pulmonary neuroendocrine tumours and observed significant improvement of symptoms (cough) in four patients treated with somatostatin analogues. Similar results have recently been reported by CARR et al. [21]. Similar to gastrointestinal carcinoids, cases of DIPNECH displaying activation of the mTOR pathway, particularly those experiencing disease progression despite treatment, may potentially
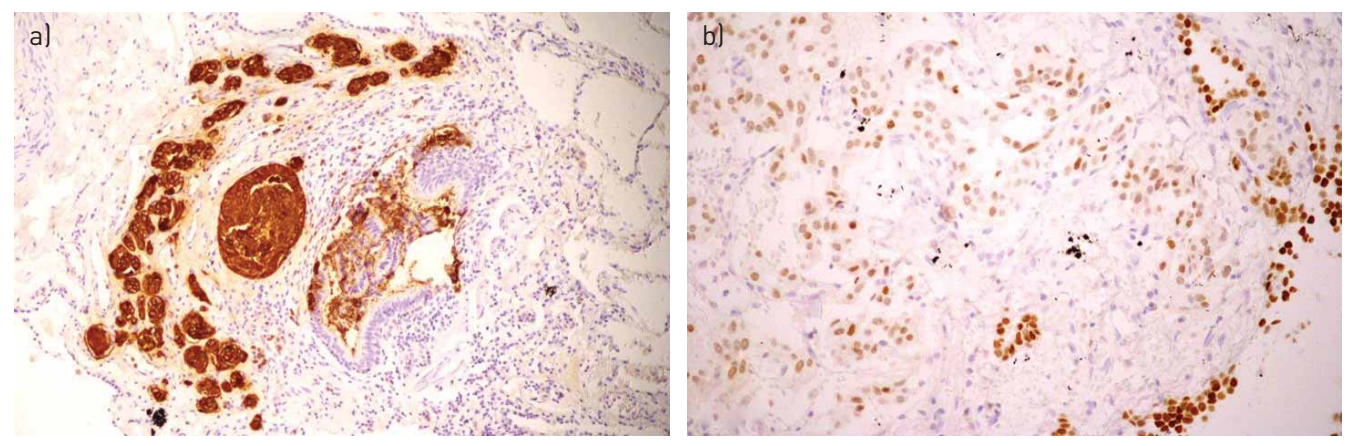

FIGURE 5 Neuroendocrine cells express a) chromogranin A and b) thyroid transcription factor (TTF)-1 at immunohistochemistry. Note the weaker staining of TTF-1 when compared with normal pneumocytes. 
benefit from mTOR inhibitors [42, 43]. However, although the activation of the mTOR pathway in DIPNECH appears to be similar to that observed in sporadic carcinoid tumours $[42,43]$, at present there are no robust data on the safety and efficacy of mTOR inhibitors in patients with DIPNECH.

The prognosis of DIPNECH is highly variable. Indeed, while the majority of cases follow a chronic, slowly progressive or stable clinical course, those characterised by marked constrictive bronchiolitis may progress to severe airflow obstruction and respiratory failure requiring lung transplantation $[5,7,20,21]$. Treatment and prognosis of multifocal NECH vary based on the setting in which neuroendocrine cell proliferation occurs. In cases of carcinoid tumours, treatment and prognosis depend on tumour stage and histology.

Tables 3 and 4 summarise the main features of patients with DIPNECH (i.e. demographics, disease duration, treatment, long-term outcome, most common presenting symptoms, lung function, and radiographic and histological findings) based on a comprehensive review of the literature.

\section{Discussion}

The definition of DIPNECH as proposed by the WHO classification of lung tumours encompasses not only the condition initially described by AGUAYo et al. [2] in 1992, but also a variety of other conditions in which neuroendocrine cell proliferation can be encountered [82]. According to the original report by AGUAYo et al. [2], DIPNECH is a disorder with a strong female preponderance characterised histologically by a diffuse, bronchiolocentric proliferation of neuroendocrine cells at the periphery of the lung, radiologically by ground-glass opacity, mosaic attenuation with air trapping, bronchial wall thickening and pulmonary nodules, and clinically by symptoms of airflow limitation secondary to constrictive obliterative bronchiolitis. We believe the term DIPNECH syndrome should be restricted to this subset of patients and suggest the term "DIPNECH with airway disease" to better define them.

At present, the term DIPNECH is used in two completely different scenarios. The first and most common is a pathology-based setting in which DIPNECH is defined by the presence of foci of neuroendocrine cell hyperplasia and tumourlets, usually in the context of a carcinoid tumour. These cases do not have clinical or radiological features of airway disease, and their treatment and prognosis depend on the stage and type of the associated carcinoid tumour. Therefore, most cases of DIPNECH diagnosed histologically in routine practice (and the majority of those reported in the literature to date) merely represent an incidental finding in asymptomatic patients without significant radiological abnormalities $[6,7,10]$. Indeed, in most of the cases reported by DAviEs et al. [7] and MARCHEVsKy et al. [10], DIPNECH was an incidental finding in asymptomatic patients with carcinoid tumours. Scattered neuroendocrine cell proliferation in the parenchyma adjacent to the tumour is observed in the majority of peripherally located carcinoid tumours of the lung $[1,12,13]$. However, this finding largely depends on the number of samples taken for histological examination. In fact, although more frequent in neuroendocrine neoplasms, $\mathrm{NECH}$ and tumourlets are incidentally observed in $14 \%$ of lobectomies from patients with nonsmall cell lung cancer [83]. In this regard, and consistent with the data from Rizvi et al. [83] and Miller and Muller [12], multiple foci of $\mathrm{NECH}$ and/or tumourlets were observed in all cases of surgically resected peripheral carcinoids (18 out of 18) where at least three samples taken from the "normal" lung tissue surrounding the tumour were available (G.Rossi, unpublished observation). Notably, in this latter case series only two (11\%) out of 18 patients had mosaic attenuation on chest CT (an indirect sign of constrictive bronchiolitis, which was confirmed histologically) and only one (6\%) had symptoms caused by airflow obstruction.

\section{Open questions and our proposal}

MARCHEvsky et al. [10] have recently suggested the presence of multifocal NECH combined with more than three tumourlets as the minimum pathological criteria for the diagnosis of DIPNECH. Although the proposed diagnostic criteria are more reliable and reproducible, they are based on morphological features only, thus somehow limiting DIPNECH to a pathological entity [10]. Using the same pathological criteria, WirTsCHAFTER et al. [6] have evaluated 30 patients with DIPNECH and systematically reviewed 169 cases reported in the English literature. They confirmed that the criteria adopted to diagnose DIPNECH differ significantly across published case series and case reports. In addition, they observed that only 55 (28\%) out of 199 cases in their systematic review had obliterative or constrictive bronchiolitis, thus providing further support to the conceptual separation of DIPNECH from other forms of NECH of the lung. An alternative is to consider DIPNECH as synonymous with Aguayo's disease. However, overall, only a minority of patients with DIPNECH have clinically relevant airflow obstruction, even in cases with histological evidence of increased airway wall thickening, chronic inflammation and constrictive obliterative bronchiolitis [7]. In order to restrict the diagnosis of DIPNECH to a more homogenous subset of patients, we propose the term "DIPNECH syndrome" or "DIPNECH with airway disease", to indicate patients with a chronic history of respiratory symptoms (cough and dyspnoea), obstructive airway disease and radiological abnormalities. In this setting, treatment and prognosis mainly depend on the severity of 
TABLE 3 Demographics, disease duration, treatment and long-term outcome in patients with DIPNECH

\begin{tabular}{|c|c|c|c|c|c|c|c|c|c|c|}
\hline \multirow[t]{2}{*}{ First author [ref.] } & \multirow[t]{2}{*}{ Cases $\mathbf{n}$} & \multirow[t]{2}{*}{ Males/females $\mathrm{n}$} & \multirow[t]{2}{*}{ Age years } & \multirow{2}{*}{$\begin{array}{l}\text { Smoking history } \\
\text { current/ex/non" }\end{array}$} & \multirow[t]{2}{*}{ Disease duration" } & \multicolumn{2}{|c|}{ Treatment $^{+}$} & \multicolumn{3}{|c|}{ Long-term outcome $\mathrm{e}^{\S}$} \\
\hline & & & & & & Yes & No & Improved & Stable & Progressed \\
\hline Case reports $[20,24,29,30,48-73]$ & 30 & $3 / 27$ & $61(36-81)$ & $2 / 8 / 20$ & $7.8(0-25)$ years & 14 & 10 & 4 & 16 & 4 \\
\hline ABRANTES [74] & 3 & & $60 / 72 / 80$ & & $\begin{array}{c}3 \text { months } / 6 \text { months/ } \\
6 \text { months }\end{array}$ & 0 & 3 & 0 & 3 & 0 \\
\hline Aguayo [2] & 6 & $2 / 4$ & $57(22-76)$ & $0 / 0 / 6$ & $14.5(3-20)$ years & 4 & 2 & 0 & 5 & 1 \\
\hline AuBRY [13] & 28 & $2 / 26$ & $65(45-84)$ & $1 / 12 / 15$ & & & & & 10 & 2 \\
\hline BANIAK [75] & 6 & $1 / 5$ & 72 (62-92) & $3 / 0 / 2$ & $5.4(0-25)$ years & & & & & \\
\hline CARR $_{\text {A21] }}$ & 30 & $0 / 30$ & $62(45-75)$ & $0 / 11 / 19$ & Often $>10$ years & $30^{f}$ & & & & $11^{\# \#}$ \\
\hline Chauhan [47] & 5 & $0 / 5$ & $65(56-72)$ & & & $4^{\text {ๆศก }}$ & 1 & 4 & & \\
\hline Coletta [76] & 3 & & $49 / 76 / 64$ & $0 / 0 / 3$ & $\begin{array}{c}2 \text { weeks/ } 6 \text { months/ } \\
10 \text { years }\end{array}$ & 3 & 0 & 0 & 2 & 1 \\
\hline DAVIES [7] & 19 & $4 / 15$ & $57(46-78)$ & $1 / 4 / 12$ & Mean 8.5 years & 2 & 8 & & 11 & 2 \\
\hline GoRSHTEIN [77] & 11 & $0 / 11$ & $63(53-74)$ & $0 / 2 / 9$ & $15.8(2-15)$ years & $6^{++}$ & 5 & 0 & 5 & 6 \\
\hline Gosney [23] & 7 & $1 / 6$ & $65(42-76)$ & & & & & & & \\
\hline LeE [32] & 5 & $0 / 5$ & $54(45-63)$ & & $>10$ years & & & & & \\
\hline LIM [78] & 2 & & $72 / 56$ & $0 / 2 / 0$ & & & & & & \\
\hline MARCHEVSKY [10] & 30 & & & & & & & 0 & 21 & 5 \\
\hline ReYes [79] & 2 & & $67 / 40$ & & & 2 & 0 & 2 & 0 & 0 \\
\hline RoWAN [80] & 2 & & $45 / 52$ & $0 / 0 / 1$ & Chronic & & & & & \\
\hline SWIGRIS [81] & 4 & $0 / 4$ & $59(47-66)$ & $0 / 0 / 4$ & $\begin{array}{l}\text { Since childhood/ } \\
\text { adolescence in two } \\
\text { patients }\end{array}$ & & & 1 & 3 & 0 \\
\hline Zноч [26] & 2 & & $59 / 67$ & $0 / 0 / 2$ & & 0 & $2^{\S \S}$ & 0 & 2 & 0 \\
\hline
\end{tabular}

Data are presented as mean (range), unless otherwise stated. Only studies that reported, along with histological findings, at least two of the following were included: presence or absence of symptoms, radiographic abnormalities and long-term outcome. DIPNECH: diffuse idiopathic pulmonary neuroendocrine cell hyperplasia. \#: data may not be available for all patients or may be difficult to ascertain from individual studies: ${ }^{\text {?: }}$ data may not be available for all patients or may be difficult to ascertain from individual studies: ${ }^{+}$: mainly incudes bronchodilators and inhaled or systemic corticosteroids, data may not be available for all patients or may be difficult to ascertain from individual studies; ${ }^{\S}$ : data may not be available for all patients or may be difficult to ascertain from individual studies; ${ }^{f}$ : treatment consisted of oral steroids and/or inhaled steroids and/or octreotide; ${ }^{\# \#}$ : the authors reported progressive decline in most

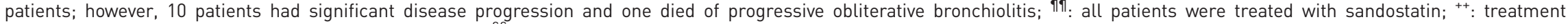
consisted of octreotide acetate $(n=5)$ and lanreotide $(n=1)$; $\$$ : both patients underwent double lung transplantation. 
TABLE 4 Most common symptoms and lung function, radiographic and histologic findings in patients with DIPNECH

\begin{tabular}{|c|c|c|c|c|c|c|c|c|c|c|c|}
\hline \multirow[t]{2}{*}{ First author [ref.] } & \multirow[t]{2}{*}{ Cases } & \multicolumn{2}{|c|}{$\begin{array}{l}\text { Respiratory } \\
\text { symptoms }\end{array}$} & \multicolumn{3}{|c|}{ Lung function test ${ }^{\Uparrow}$} & \multicolumn{4}{|c|}{ HRCT findings ${ }^{+}$} & \multirow[t]{2}{*}{ Pathology } \\
\hline & & Yes & No & Normal & Obstructive & $\begin{array}{l}\text { Mixed/ } \\
\text { restrictive }\end{array}$ & Nodules & $\begin{array}{c}\text { Air } \\
\text { trapping }\end{array}$ & $\begin{array}{c}\text { Mosaic } \\
\text { attenuation }\end{array}$ & Other ${ }^{\S}$ & \\
\hline Case reports $[20,24,29,30,48-73]$ & 30 & 26 & 4 & 8 & 18 & 4 & 23 & 8 & 7 & 10 & $\begin{array}{c}\mathrm{NECH} \pm \text { tumourlets, } \pm \text { carcinoid } \\
\text { tumours } \pm \text { constrictive } \\
\text { bronchiolitis } \pm \text { peribronchial } \\
\text { fibrosis }\end{array}$ \\
\hline Abrantes [74] & 3 & 3 & 0 & 2 & 1 & 0 & 3 & & & & $\begin{array}{l}\mathrm{NECH} \pm \text { tumourlets } \pm \\
\text { carcinoid tumours }\end{array}$ \\
\hline Aguayo [2] & 6 & 6 & 0 & 1 & 4 & 1 & 5 & 1 & & 1 & $\mathrm{NECH} \pm$ carcinoid tumours \\
\hline AuBRY [13] & 28 & 19 & 9 & 6 & 16 & & 26 & 1 & 1 & 2 & $\begin{array}{l}\mathrm{NECH} \pm \text { tumourlets, } \\
\pm \text { carcinoid tumours }\end{array}$ \\
\hline BANIAK [75] & 6 & 6 & 0 & & 3 & & 4 & & & 1 & $\begin{array}{l}\mathrm{NECH} \pm \text { tumourlets } \pm \\
\text { invasive carcinoma }\end{array}$ \\
\hline $\mathrm{C}_{\mathrm{ARR}}[21]$ & 30 & 30 & 0 & 0 & 26 & 4 & 26 & 25 & 21 & 20 & $\begin{array}{c}\mathrm{NECH}+\text { tumourlets } \pm \text { carcinoid } \\
\text { tumours } \pm \text { constrictive } \\
\text { bronchiolitis }\end{array}$ \\
\hline Chauhan [47] & 5 & 5 & 0 & & & & 5 & 0 & 0 & 0 & $\mathrm{NECH} \pm$ carcinoid tumour \\
\hline Coletta [76] & 3 & 3 & 0 & 0 & 3 & 0 & 2 & 3 & & 1 & $\begin{array}{l}\text { NECH } \pm \text { carcinoid tumours } \pm \\
\text { constrictive bronchiolitis } \pm \\
\text { bronchiolitis obliterans }\end{array}$ \\
\hline Davies [7] & 19 & 9 & 10 & 5 & 8 & 4 & 18 & 5 & 5 & 4 & $\begin{array}{l}\mathrm{NECH} \pm \text { tumourlets } \pm \\
\text { constrictive bronchiolitis }\end{array}$ \\
\hline GoRshtein [77] & 11 & 6 & 5 & 2 & 7 & & 11 & 0 & 0 & 2 & $\mathrm{NECH}$ \\
\hline GOSNEY [23] & 7 & 4 & 3 & & & & 7 & & & & $\begin{array}{l}\mathrm{NECH} \pm \text { carcinoid tumours } \pm \\
\text { constrictive bronchiolitis }\end{array}$ \\
\hline LeE [32] & 5 & 5 & 0 & 0 & 3 & 2 & 3 & 5 & 5 & 5 & $\begin{array}{l}\mathrm{NECH} \pm \text { tumorlets, } \\
\pm \text { carcinoid tumours }\end{array}$ \\
\hline Lim [78] & 2 & 2 & 0 & & & 1 & 2 & 0 & 0 & 0 & $\begin{array}{l}\mathrm{NECH} \pm \text { tumourlets } \pm \\
\text { carcinoid tumours }\end{array}$ \\
\hline MARCHEVSKY [10] & 30 & 22 & 8 & 7 & 4 & 2 & 28 & 0 & 0 & 3 & $\begin{array}{l}\mathrm{NECH}+\text { tumourlets } \pm \\
\text { carcinoid tumours }\end{array}$ \\
\hline Reyes [79] & 2 & 2 & 0 & & & & 0 & 0 & 1 & 1 & $\mathrm{NECH} \pm$ tumourlets \\
\hline RoWAN [80] & 2 & 2 & 0 & 0 & 1 & 1 & 0 & 0 & 0 & 2 & $\begin{array}{l}\mathrm{NECH}+\text { focal obliterative } \\
\text { bronchiolitis }\end{array}$ \\
\hline SWIGRIS [81] & 4 & 3 & & 0 & 3 & 1 & 4 & 0 & 0 & 0 & $\begin{array}{l}\mathrm{NECH}+\text { tumourlets } \pm \\
\text { carcinoid tumours }\end{array}$ \\
\hline Zнои [26] & 2 & 2 & 0 & 0 & 2 & 0 & 2 & 0 & 0 & 2 & $\begin{array}{l}\mathrm{NECH}+\text { tumourlets + } \\
\text { carcinoid tumours }\end{array}$ \\
\hline
\end{tabular}

Data are presented as $\mathrm{n}$. Only studies that reported, along with histological findings, at least two of the following were included: presence or absence of symptoms, radiographic abnormalities and long-term outcome. DIPNECH: diffuse idiopathic pulmonary neuroendocrine cell hyperplasia; HRCT: high-resolution computed tomography; NECH: neuroendocrine cell hyperplasia. " : mainly include cough, dyspnoea, wheezing and reduced exercise tolerance, data may not be available for all patients or may be difficult to ascertain in individual studies; " : data may not be available for all patients or may be difficult to ascertain in individual studies; ${ }^{+}$: HRCT may display more than one pattern in individual patients, findings may not be available for all patients or may be difficult to ascertain in individual studies; ${ }^{\S}$ : findings include small airway disease, bronchiectasis/bronchial dilatation, bronchial wall thickening, ground-glass opacities, hilar or mediastinal adenopathy, interlobular septal thickening, honeycombing, diffuse cystic changes, emphysema and microcalcifications. 


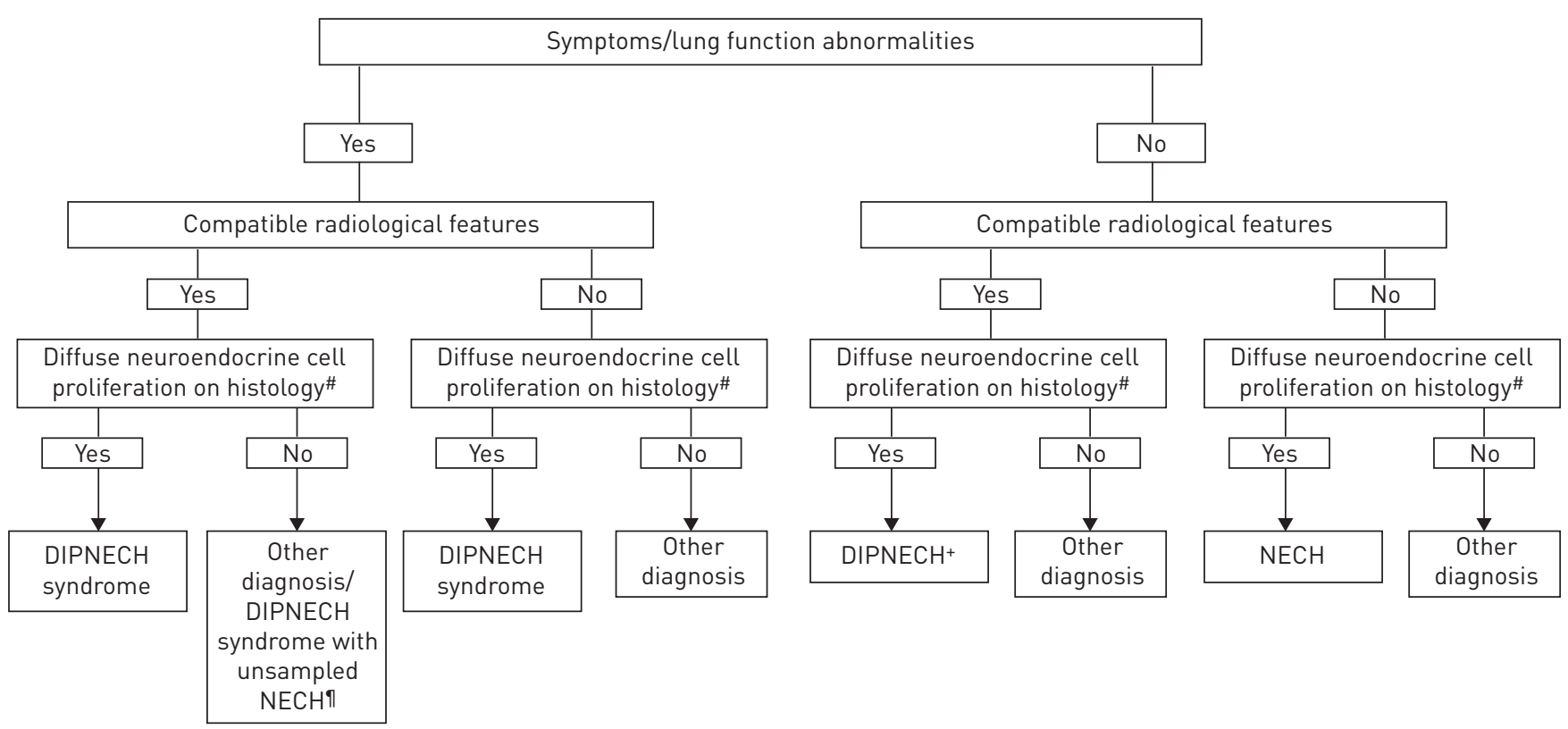

FIGURE 6 Proposed diagnostic flow chart of diffuse idiopathic pulmonary neuroendocrine cell hyperplasia (DIPNECH) syndrome (Aguayo's disease) integrating clinical, radiological and histologic data. $\mathrm{NECH}$ : neuroendocrine cell hyperplasia. \#: the presence of constrictive bronchiolitis on histology strongly supports a diagnosis of DIPNECH syndrome; " if there is no evidence of NECH on histology, repeating the biopsy, whenever possible, is strongly recommended; ${ }^{+}$: patients in this group may progress to clinically significant disease (e.g. DIPNECH syndrome).

constrictive obliterative bronchiolitis. Needless to say, there may be occasional cases with overlapping features of both forms. However, we believe it is important to keep Aguayo's disease (e.g. DIPNECH with airway disease) separate from tumourlets/carcinoid-related $\mathrm{NECH}$, which represents a purely pathological entity, because of the different clinical behaviour and prognosis of the two forms in most cases. In a recent retrospective study of 30 patients with DIPNECH, CARR et al. [21] assessed longitudinal data on pulmonary physiology, chest CT imaging and treatment, and adopted a multidisciplinary approach to diagnosis and management. They proposed a set of diagnostic criteria based on patient demographics, clinical features, pulmonary function tests, high-resolution computed tomography appearance, transbronchial and surgical lung biopsy findings and serum markers (i.e. chromogranin A) [21]. Of note, CARR et al. [21] suggest that, in the appropriate clinical setting, transbronchial biopsy may be sufficient to diagnose DIPNECH. Indeed, in their experience, when available, transbronchial biopsy confirmed the presence of a neuroendocrine cell proliferation in six $(60 \%)$ out of 10 cases.

A careful integration of clinical, functional and imaging data along with the histological demonstration of constrictive bronchiolitis akin to neuroendocrine cell proliferation (or isolated neuroendocrine cell proliferation when examining transbronchial biopsy samples) is mandatory to establish a diagnosis of DIPNECH. Our proposed diagnostic flow chart for differentiating DIPNECH syndrome from secondary diffuse NECH or other mimickers of DIPNECH is summarised in figure 6. In principle, in order to formulate a secure diagnosis of DIPNECH/Aguayo's disease, histological NECH should accompany clinical/functional and/or radiological abnormalities, although classical clinical and radiological appearance may be highly suggestive (though not diagnostic) of DIPNECH.

In summary, DIPNECH (as defined by the 2015 WHO classification of lung tumours) represents a sort of wastebasket that includes incidental cases of scattered neuroendocrine cell proliferation observed in the context of various pulmonary diseases, forms associated with carcinoid tumours, and the distinct patient subset originally described by AGUAYO et al. [2]. The adoption of stringent clinico-pathological and radiological criteria when dealing with neuroendocrine cell proliferation of the lung may allow for the identification of patients with Aguayo's disease. We consider that, in this setting, the term "DIPNECH syndrome" or "DIPNECH with airway disease" is more appropriate.

\section{References}

$1 \quad$ Felton WL 2nd, Liebow AA, Lindskog GE. Peripheral and multiple bronchial adenomas. Cancer 1953; 6: 555-566.

2 Aguayo SM, Miller YE, Waldron JA Jr, et al. Brief report: idiopathic diffuse hyperplasia of pulmonary neuroendocrine cells and airways disease. $N$ Engl J Med 1992; 327: 1285-1288.

3 Sunday ME. Pulmonary neuroendocrine cells and lung development. Endocr Pathol 1996; 7: 173-201.

4 Linnoila RI. Functional facets of the pulmonary neuroendocrine system. Lab Invest 2006; 86: 425-444. 
5 Gosney JR, Austin JHM, Jett J, et al. Diffuse pulmonary neuroendocrine cell hyperplasia. In: Travis WD Brambilla E, Burke AP, et al., eds. WHO classification of tumours of the lung, pleura, thymus and heart. Lyon, IARC Press, 2015; pp. 78-79.

6 Wirtschafter E, Walts AE, Liu ST, et al. Diffuse idiopathic pulmonary neuroendocrine cell hyperplasia of the lung (DIPNECH): current best evidence. Lung 2015; 193: 659-667.

7 Davies SJ, Gosney JR, Hansell DM, et al. Diffuse idiopathic pulmonary neuroendocrine cell hyperplasia: an under-recognised spectrum of disease. Thorax 2007; 62: 248-522.

8 Benson RE, Rosado-de-Christenson ML, Martínez-Jiménez S, et al. Spectrum of pulmonary neuroendocrine proliferations and neoplasms. Radiographics 2013; 33: 1631-1649.

9 Gould VE, Lee I, Warren WH. Immunohistochemical evaluation of neuroendocrine cells and neoplasms of the lung. Pathol Res Pract 1988; 183: 200-213.

10 Marchevsky AM, Wirtschafter E, Walts AE. The spectrum of changes in adults with multifocal pulmonary neuroendocrine proliferations: what is the minimum set of pathologic criteria to diagnose DIPNECH? Hum Pathol 2015; 46: 176-181.

11 Gould VE, Linnoila IR, Memoli VA, et al. Neuroendocrine components of the bronchopulmonary tract: hyperplasia, dysplasia, and neoplasms. Lab Invest 1983; 49: 519-537.

12 Miller RR, Muller NL. Neuroendocrine cell hyperplasia and obliterative bronchiolitis in patients with peripheral carcinoid tumours. Am J Surg Pathol 1995; 19: 653-658.

13 Aubry MC, Thomas CF Jr, Jett JR, et al. Significance of multiple carcinoid tumors and tumorlets in surgical lung specimens: analysis of 28 patients. Chest 2007; 131: 1635-1643

14 Gosney JR, Sissons MCJ, Allibone RO, et al. Pulmonary endocrine cells in chronic bronchitis and emphysema. J Pathol 1989; 157: 127-133.

15 Canessa PA, Santini D, Zanelli M, et al. Pulmonary tumourlets and microcarcinoids in bronchiectasis. Monaldi Arch Chest Dis 1997; 52: 138-139.

16 Pelosi G, Zancanaro C, Sbabo L, et al. Development of innumerable neuroendocrine tumorlets in pulmonary lobe scarred by intralobar sequestration. Immunohistochemical and ultrastructural study of an unusual case. Arch Pathol Lab Med 1992; 116: 1167-1174.

17 Aguayo SM, King TE Jr, Waldron JA Jr, et al. Increased pulmonary neuroendocrine cells with bombesin-like immunoreactivity in adult patients with eosinophilic granuloma. J Clin Invest 1990; 86: 838-844.

18 Dewan M, Malatani TS, Osinowo O, et al. Carcinoid tumourlets associated with diffuse bronchiectasis and intralobar sequestration. J R Soc Promot Health 2000; 120: 192-195.

$19 \mathrm{He} \mathrm{P}, \mathrm{Gu} \mathrm{X}, \mathrm{Wu} \mathrm{Q}$, et al. Pulmonary carcinoid tumorlet without underlying lung disease: analysis of its relationship to fibrosis. J Thorac Dis 2012; 4: 655-658.

20 Nassar AA, Jaroszewski DE, Helmers RA, et al. Diffuse idiopathic pulmonary neuroendocrine cell hyperplasia: a systematic overview. Am J Respir Crit Care Med 2011; 184: 8-16.

21 Carr LL, Chung JH, Achcar RD, et al. The clinical course of diffuse idiopathic pulmonary neuroendocrine cell hyperplasia. Chest 2015; 147: 415-422.

22 Travis WD. Advances in neuroendocrine lung tumors. Ann Oncol 2010; 21: Suppl 7, vii65-vii71.

23 Gosney JR, Williams IJ, Dodson AR, et al. Morphology and antigen expression profile of pulmonary neuroendocrine cells in reactive proliferations and diffuse idiopathic pulmonary neuroendocrine cell hyperplasia (DIPNECH). Histopathology 2011; 59: 751-762.

24 Falkenstern-Ge RF, Kimmich M, Friedel G, et al. Diffuse idiopathic pulmonary neuroendocrine cell hyperplasia: 7-year follow-up of a rare clinicopathologic syndrome. J Cancer Res Clin Oncol 2011; 137: 1495-1498.

25 Sheerin N, Harrison NK, Sheppard MN, et al. Obliterative bronchiolitis caused by multiple tumourlets and microcarcinoids successfully treated by single lung transplantation. Thorax 1995; 50: 207-279.

26 Zhou H, GE Y, Janssen B, et al. Double lung transplantation for diffuse idiopathic pulmonary neuroendocrine cell hyperplasia. J Bronchology Interv Pulmonol 2014; 21: 342-345.

27 Arioglu E, Doppman J, Gomes M, et al. Cushing's syndrome caused by corticotropin secretion by pulmonary tumorlets. N Engl J Med 1998; 339: 883-886.

28 Tsuchihashi T, Yamaguchi $\mathrm{K}$, Abe $\mathrm{K}$, et al. Production of immunoreactive corticotropin-releasing hormone in various neuroendocrine tumors. Jpn J Clin Oncol 1992; 22: 232-237.

29 Fessler MB, Cool CD, Miller YE, et al. Idiopathic diffuse hyperplasia of pulmonary neuroendocrine cells in a patient with acromegaly. Respirology 2004; 9: 274-277.

30 Oba H, Nishida K, Takeuchi S, et al. Diffuse idiopathic pulmonary neuroendocrine cell hyperplasia with a central and peripheral carcinoid and multiple tumorlets: a case report emphasizing the role of neuropeptide hormones and human gonadotropin- $\alpha$. Endocr Pathol 2013; 24: 220-822.

31 Brown MJ, English J, Müller NL. Bronchiolitis obliterans due to neuroendocrine hyperplasia: high-resolution CT-pathologic correlation. Am J Roentgenol AJR 1997; 168: 1561-1562.

32 Lee JS, Brown KK, Cool C, et al. Diffuse pulmonary neuroendocrine cell hyperplasia: radiologic and clinical features. J Comput Assist Tomogr 2002; 26: 180-184.

33 Chassagnon G, Favelle O, Marchand-Adam S, et al. DIPNECH: when to suggest this diagnosis on CT. Clin Radiol 2015; 70: 317-325.

34 Rekhtman N. Neuroendocrine tumors of the lung: an update. Arch Pathol Lab Med 2010; 134: 1628-1638.

35 Degan S, Lopez GY, Kevill K, et al. Gastrin-releasing peptide, immune responses, and lung disease. Ann N Y Acad Sci 2008; 1144: 136-147.

36 Cohen AJ, King TE Jr, Gilman LB, et al. High expression of neutral endopeptidase in idiopathic diffuse hyperplasia of pulmonary neuroendocrine cells. Am J Respir Crit Care Med 1998; 58: 1593-1599.

37 Du EZ, Goldstraw P, Zacharias J, et al. TTF-1 expression is specific for lung primary in typical and atypical carcinoids: TTF-1-positive carcinoids are predominantly in peripheral location. Hum Pathol 2004; 35: 825-831.

38 Pelosi G, Rossi G, Cavazza A, et al. Np63 (p40) distribution inside lung cancer: a driver biomarker approach to tumor characterization. Int J Surg Pathol 2013; 21: 229-239.

39 Sturm N, Rossi G, Lantuejoul S, et al. 34ßE12 expression along the whole spectrum of neuroendocrine proliferations of the lung, from neuroendocrine cell hyperplasia to small cell carcinoma. Histopathology 2003; 42: 156-166. 
142: 802-805

63 Dvorackova J, Macak J, Buzrla P. Diffuse idiopathic pulmonary neuroendocrine cell hyperplasia: case report and review of literature. Cesk Patol 2013; 49: 99-102.

64 Killen H. DIPNECH presenting on a background of malignant melanoma: new lung nodules are not always what they seem. BMJ Case Rep 2014; 2014: pii: bcr2014203667.

65 Patel C, Tirukonda P, Bishop R, et al. Diffuse idiopathic pulmonary neuroendocrine cell hyperplasia (DIPNECH) masquerading as metastatic carcinoma with multiple pulmonary deposits. Clin Imaging 2012; 36: 833-836.

66 Sanaee MS, O’Byrne PM, Nair P. Diffuse idiopathic pulmonary neuroendocrine hyperplasia, chronic eosinophilic pneumonia, and asthma. Eur Respir J 2009; 34: 1489-1492.

67 Ge Y, Eltorky MA, Ernst RD, et al. Diffuse idiopathic pulmonary neuroendocrine cell hyperplasia. Ann Diagn Pathol 2007; 11: 122-126.

68 Singhania N, Liang Q, Cool C, et al. Diffuse idiopathic pulmonary neuroendocrine cell hyperplasia (DIPNECH) in a patient with cough and dyspnea resistant to standard therapy. J Allergy Clin Immunol 2007; 119: Suppl, S173.

69 Alqdah M, Jokhio S, El-zammar O. Diffuse idiopathic pulmonary neuroendocrine hyperplasia (DIPNECH). Chest 2007; 132: 711a.

70 Terminella L, Duarte A. Obliterative bronchiolitis due to diffuse idiopathic pulmonary neuroendocrine cell hyperplasia. Chest 2005; 128: 467S-468S.

71 Erdini F, Spaltro AA, Ruiu A, et al. Diffuse idiopathic pulmonary neuroendocrine cell hyperplasia (DIPNECH) and multiple pulmonary epithelioid hemangioendothelioma (PEH): a case report. Pathologica 2015; 107: 37-42.

72 Karnatovskaia LV, Khoor A, Mira-Avendano I. Sarcoid-like reaction in diffuse idiopathic pulmonary neuroendocrine cell hyperplasia. Am J Respir Crit Care Med 2014; 190: e62-e63.

73 Ofikwu G, Mani VR, Rajabalan A, et al. A rare case of diffuse idiopathic pulmonary neuroendocrine cell hyperplasia. Case Rep Surg 2015; 2015: 318175.

74 Abrantes C, Oliveira RC, Saraiva J, et al. Pulmonary peripheral carcinoids after diffuse idiopathic pulmonary neuroendocrine cell hyperplasia and tumorlets: report of 3 cases. Case Rep Pulmonol 2015; 2015: 851046.

75 Baniak NM, Wilde B, Kanthan R. Diffuse idiopathic pulmonary neuroendocrine cell hyperplasia (DIPNECH) - an uncommon precursor of a common cancer? Pathol Res Pract 2016; 212: 125-129.

76 Coletta EN, Voss LR, Lima MS, et al. Diffuse idiopathic pulmonary neuroendocrine cell hyperplasia accompanied by airflow obstruction. J Bras Pneumol 2009; 35: 489-494.

77 Gorshtein A, Gross DJ, Barak D, et al. Diffuse idiopathic pulmonary neuroendocrine cell hyperplasia and the associated lung neuroendocrine tumors: clinical experience with a rare entity. Cancer 2012; 118: 612-619. 
78 Lim C, Stanford D, Young I, et al. Diffuse idiopathic pulmonary neuroendocrine cell hyperplasia: a report of two cases. Pathol Int 2010; 60: 538-541.

79 Reyes LJ, Majó J, Perich D, et al. Neuroendocrine cell hyperplasia as an unusual form of interstitial lung disease. Respir Med 2007; 101: 1840-1843.

80 Rowan C, Hansell DM, Renzoni E, et al. Diffuse cystic lung disease of unexplained cause with coexistent small airway disease: a possible causal relationship? Am J Surg Pathol 2012; 36: 228-234.

81 Swigris J, Ghamande S, Rice TW, et al. Diffuse idiopathic neuropathic cell hyperplasia an interstitial lung disease with airway obstruction. J Bronchol 2005; 12: 62-65.

82 Miller MA, Mark GJ, Kanarek D. Multiple peripheral pulmonary carcinoids and tumorlets of carcinoid type, with restrictive and obstructive lung disease. Am J Med 1978; 65: 373-378.

83 Rizvi SM, Goodwill J, Lim E, et al. The frequency of neuroendocrine cell hyperplasia in patients with pulmonary neuroendocrine tumours and non-neuroendocrine cell carcinomas. Histopathology 2009; 55: 332-337. 